\title{
Natural Gas Hydrate Prediction and Prevention Methods of City Gate Stations
}

\author{
Lili Zuo $\mathbb{D}^{1},{ }^{1}$ Sirui Zhao $\mathbb{D}^{1},{ }^{1}$ Yaxin Ma $\mathbb{D}^{1},{ }^{1}$ Fangmei Jiang $\mathbb{D},{ }^{2}$ and Yue Zu $\mathbb{D}^{2}$ \\ ${ }^{1}$ National Engineering Laboratory for Pipeline Safety, MOE Key Laboratory of Petroleum Engineering, \\ Beijing Key Laboratory of Urban Oil and Gas Distribution Technology, China University of Petroleum-Beijing, \\ Beijing 102249, China \\ ${ }^{2}$ Pipe China Beijing Pipeline Co., Ltd., Beijing, China \\ Correspondence should be addressed to Lili Zuo; zuolili@cup.edu.cn
}

Received 11 May 2021; Accepted 8 July 2021; Published 14 July 2021

Academic Editor: Jinyu Chen

Copyright (C) 2021 Lili Zuo et al. This is an open access article distributed under the Creative Commons Attribution License, which permits unrestricted use, distribution, and reproduction in any medium, provided the original work is properly cited.

\begin{abstract}
During the process of distributing natural gas to urban users through city gate stations, hydrate is easy to form due to the existence of throttling effect which causes safety risks. To handle this problem, a program to quickly calculate hydrate prediction and prevention methods for city gate stations is developed. The hydrate formation temperature is calculated through the Chen-Guo model, and the Peng-Robinson equation of state combined with the balance criterion is used to analyze the water condensation in the throttling process. The Wilson activity coefficient model is used to calculate the mass fraction in the liquid phase of thermodynamic inhibitors for preventing hydrates. Considering the volatility of inhibitors, the principle of isothermal flash has been utilized to calculate the total injection volume of the inhibitor. Moreover, the effects of commonly used methanol and ethylene glycol inhibitors are discussed. In terms of safety and sustainability, the ethanol inhibitor, which is considered for the first time, exhibited better prevention and control effects under conditions with relatively high temperature and low pressure after throttling. Combined with the actual working conditions of a gate station, methanol has the best inhibitory effect, followed by ethylene glycol. From an economic point of view, the benefits of the gas phase of the inhibitor during the delivery of natural gas are obvious; therefore, the method of methanol injection is recommended for hydrate prevention. If the gas phase benefits of the inhibitor are not considered, the ethylene glycol injection method becomes more economical.
\end{abstract}

\section{Introduction}

Due to the uneven distribution of resources, natural gas is mainly transported through long-distance pipelines and distributed to urban users through city gate stations. Considering the existence of throttling effect, the pressure regulation on the city gate station will produce a certain temperature drop. If the water dew point of gas is high, the water is likely to condensate during the pressure regulation, leading to the formation of hydrates and triggering a series of safety accidents to both stations and urban users [1,2], such as hydrate blockage in the pressure regulating valve, resulting in a drop in the gas supply pressure to urban users. Therefore, in order to ensure safe gas supply to urban users, it is necessary to study the prediction and prevention methods of hydrate formation and to obtain a safe, environment-friendly, and economical thermodynamic inhibitor for city gate stations.

The formation of hydrates usually needs to meet three conditions: (1) the water condition that indicates enough liquid water in the system; (2) reaching the temperature and pressure conditions for hydrate formation; and, (3) the gas flow is unstable, and there are hydrate seeds. The first condition is mainly based on the phase equilibrium theory [3]. The Soave-Redlich-Kwong (SRK) or Peng-Robinson (PR) equation of state (EOS) can be used to calculate and analyze the water content and water condensation in the natural gas transportation process $[4,5]$. Temperature and pressure conditions are mainly studied by the thermodynamic model. Under certain temperature 
and pressure conditions, when the pore occupancy rate reaches a certain level, hydrate crystals can exist stably. According to the different structures, hydrate crystals can be divided into three forms: type I, type II, and type $H$, of which type I hydrate and type II hydrate unit cells are composed of two different sizes of cage cavities, and the $H$ type hydrate unit cell is composed of three different sizes of cage cavities [6]. At present, the thermodynamic models of hydrate formation can be divided into two main categories: the first is the van der Waals-Platteeuw [7] model based on the isotherm adsorption theory; the second is the Chen-Guo model [8] based on the mechanism of hydrate formation. In addition to the strict thermodynamic model and in order to facilitate the calculation efficiency, many researchers have proposed the correlation equations of hydrate formation temperature, pressure, and relative density [9-11], but the calculation accuracy is limited.

The prevention and control of hydrates can be started by destroying the formation conditions of hydrates. The main methods include heating, depressurization, injecting inhibitors, and dehydration. Injecting thermodynamic inhibitors to pipelines is currently the main method of gas hydrate inhibition in the oil and gas industry [12]. The hydrate formation model under the inhibitor system can be established by modifying the parameters of the Chen-Guo model [4]. At present, the more commonly used thermodynamic inhibitors are methanol and ethylene glycol. Methanol is cheap but has certain toxicity, and ethylene glycol is relatively less toxic but more expensive. For the natural gas system with methanol injected, some scholars [13] established a phase equilibrium model based on the PR EOS and stochasticnonstochastic theory, combined with its improved Holder-John hydrate model to predict the formation conditions of the hydrate containing the methanol inhibitor system. In addition, some scholars [14] used the Patel-Teja (PT) EOS combined with the Kurihara mixing rule to calculate the fugacity of each component in the gas phase and the water activity for prediction. Some scholars chose the Stryjek and Vera modification of Peng-Robinson (PRSV2) EOS combined with the nondensity-dependent (NDD) mixing rules to calculate the fugacity of water in the gas phase and the liquid phase, so as to predict the formation conditions of the hydrate containing the alcohol inhibitor system [15].

At present, the software that can be used for hydrate formation prediction and inhibitor injection volume calculation mainly includes process simulation software such as HYSYS and PVTsim software [16-18]. Although the calculation methods and theories of these commercial software are quite mature, there are still many limitations in actual use. In these commercial software, the calculation of hydrate formation prediction and inhibitor injection volume only exists as a module, and additional environmental configuration is required for calculation, which increases the complexity of software operations. Therefore, it is necessary to design a software to achieve the purpose of quick calculation for on-site personnel.
This article mainly focuses on the actual pressure regulation on site, carries on the prediction of hydrate formation and the discussion of prevention and control measures to form a program to quickly calculate hydrate formation conditions and prevention measures for city gate stations, provides reference for on-site operation and management, and realizes the goal of safe gas transmission. Based on safety and economic considerations, this article also proposes and calculates the possibility of using ethanol for inhibition.

\section{Hydrate Formation Prediction}

It can be seen from Section 1 that the formation of hydrates needs to meet the conditions of water, pressure and temperature, and disturbance at the same time. This article mainly studies the prediction of hydrate formation in the pressure regulation of the city gate station, which obviously meets the third condition. Hence, this section mainly analyzes the first two conditions.

2.1. Water Condition. The analysis of water content and water dew point of natural gas plays an important role in the safe operation of pipelines. After knowing the corresponding water dew point of natural gas under certain pressure, when the temperature is reduced to the water dew point during pressure regulation, it is the critical state of liquid water condensation. When the temperature is lower than the water dew point, the water vapor in the natural gas will condense into liquid water. At this time, the amount of water can be indicated by the change in the water content before and after the water condensation. Establishing the relationship between water dew point and water content can facilitate the analysis of water condensation by field personnel.

Calculating the water content of natural gas based on the known dry gas mole fraction, water dew point, and pressure of natural gas can be done through the calculation of gasliquid two-phase equilibrium. When the water reaches equilibrium in the gas phase and the liquid phase, it is the critical state of condensate water. At this time, the fugacity of water in the gas phase is equal to its fugacity in the liquid phase, namely,

$$
f_{v w}=f_{l w},
$$

where $f_{v w}$ refers to the fugacity of water in the gas phase (natural gas) and $f_{l w}$ refers to the fugacity of water in the liquid phase.

Fugacity is a function of pressure and temperature and needs to be calculated using the gas EOS [19]. The cubic EOS has a wide range of applications in engineering due to its simplicity and accuracy of calculation, such as the PR EOS and the SRK EOS. In this paper, the PR EOS is used in combination with the classic mixing rules for calculation.

The expression of the fugacity coefficient of water vapor in natural gas, which is derived from the PR EOS combined with the mixing rule, can be expressed as follows [20]: 


$$
\ln \varphi_{v w}=\frac{B_{i}}{B}(Z-1)-\ln (Z-B)-\frac{A}{2 \sqrt{2} B}\left(\frac{B_{i}}{B}-\frac{2}{a} \sum_{i=1}^{n} x_{i} a_{w i}\right) \cdot \ln \left[\frac{Z+(1+\sqrt{2}) B}{Z+(1-\sqrt{2}) B}\right]
$$
[20]

The fugacity coefficient of liquid water is expressed as

$$
\ln \varphi_{l w}=Z-1-\ln (Z-B)-\frac{A}{2 \sqrt{2} B} \ln \left[\frac{Z+(1+\sqrt{2}) B}{Z+(1-\sqrt{2}) B}\right],
$$

where $A, B, a$, and $a_{w i}$ are parameters in the PR EOS.

The steps to calculate the water content from the water dew point are shown in Figure 1. The steps for calculating the water dew point from the water content are similar to those shown in Figure 1, where the input condition is changed from water dew point to water content, and the iteration variable is changed from water content to water dew point.

2.2. Pressure and Temperature Conditions. The Chen-Guo model proposed by Guo Tianmin and Chen Guangjin is a thermodynamic model of hydrate formation based on statistical mechanics. Mainly, there are two kinetic processes simultaneously in the nucleation process of hydrate [21]: (1) the gas molecule complexes with water to form a stoichiometric basic hydrate that can be represented by a chemical formula and (2) the existence of the void cavity in the basic hydrate formed by gas and water that adsorbs some smaller gas molecules into it, resulting in the nonstoichiometry of the entire hydrate.

Therefore, assuming that the mixed basic hydrate is an ideal solution, Guo et al. established a basic equilibrium relationship in the natural gas hydrate system [21], namely,

$$
f_{i}=x_{i} f_{i}^{0}\left(1-\sum_{j} \theta_{j}\right)^{\alpha}
$$

where $f_{i}$ is the fugacity of component $i$ in the gas phase, which can be solved by the PR EOS, $x_{i}$ is the mole fraction of the basic hydrate formed by component $i$ in the mixed basic hydrate, and $\alpha$ is related to the hydrate structure type; when the hydrate structure is type $\mathrm{I}$, it is $1 / 3$; when the hydrate structure is type II, it is 2 .

$\theta_{j}$ is the occupancy rate of the small gas molecule $j$ in the cavity of the basic hydrate, which can be calculated according to the following formula [21]:

$$
\theta_{i}=\frac{C_{i} f_{i}}{1+\sum_{j} C_{j} f_{j}}
$$

where $C_{i}$ is the Langmuir constant of the small gas component $i$, which can be expressed in the form of the following formula [21]:

$$
C_{i}=X_{i} \exp \left(\frac{Y_{i}}{T-Z_{i}}\right)
$$

$f_{i}^{0}$ is the fugacity of the basic hydrate formed by component $i$, which can be calculated according to the following formula [21]:

$$
f_{i}^{0}=\exp \left(\frac{-\sum_{j} A_{i j} \theta_{j}}{T}\right)\left[a_{i} \exp \left(\frac{b_{i}}{T-c_{i}}\right)\right] \exp \left(\frac{\beta P}{T}\right) a_{w}^{1 / \lambda_{2}}
$$

where $A_{i j}$ is the binary interaction coefficient of the type II hydrate system, the binary interaction coefficient of type I hydrate is very small and can be ignored, $a_{i}, b_{i}$, and $c_{i}$ are parameters in the model, and the values of $\beta$ and $\lambda_{2}$ are related to the type of the hydrate structure. When the hydrate structure is type $\mathrm{I}, \beta$ is $4.242 \mathrm{~K} / \mathrm{MPa}$ and $\lambda_{2}$ is $3 / 23$. When the hydrate structure is type II, $\beta$ is $10.224 \mathrm{~K} / \mathrm{MPa}$ and $\lambda_{2}$ is $1 / 17 ; a_{w}$ is the activity of water. When the water does not contain inhibitors or electrolytes, it can be regarded as pure water, and its value is approximately 1 . When the water contains inhibitors or electrolytes, it needs to be calculated by the activity coefficient model.

After calculating the above parameters and substituting them into formula (7), the hydrate formation conditions can be predicted under the condition that the sum of the mole fractions of the components is 1 [21].

Based on the above analysis, under a given pressure, the iterative method can be used to predict the formation temperature of hydrate. If the error is within the allowable range, the iteration can be ended; otherwise, the secant method can be used to adjust the temperature value for the next iteration. When the temperature is known, the process of predicting the pressure of natural gas hydrate formation is similar to this process, except that the known condition becomes temperature and the iteration variable becomes pressure.

2.3. Judgment of Hydrate Formation for a Certain City Gate Station. In a certain city gate station, which has always made a reduction in gas supply by hydrate formation in the past, the gas flow is $30 \times 10^{4} \mathrm{Nm}^{3} / \mathrm{h}$ at the peak of gas consumption; the average inlet pressure is $3.83 \mathrm{MPa}$, the average inlet temperature is $-8^{\circ} \mathrm{C}$, the average outlet pressure is $2.05 \mathrm{MPa}$, and the outlet temperature is $-19^{\circ} \mathrm{C}$; the average water content measured when the gas enters the gate station is $79.15 \mathrm{mg} / \mathrm{Nm}^{3}$. Based on the previous analysis, the average operating condition of the gate station, the water dew point curve (water content of $79.15 \mathrm{mg} / \mathrm{Nm}^{3}$ ), and the hydrate formation curve are plotted in Figure 2.

It can be seen from Figure 2 that the average operating condition after pressure regulation at the gate station is in the hydrate formation zone; the operation point is located on the left side of the water dew point curve, indicating that there is liquid water condensation in the throttling process. At the temperature and pressure point of the curve, if the actual water content of the gas is higher than $79.15 \mathrm{mg} / \mathrm{Nm}^{3}$, there is also a risk of water condensation. The gas has the temperature, pressure, and water conditions for hydrate formation, and it is in a strong turbulent state during the throttling process. Therefore, the gate station has the risk of 


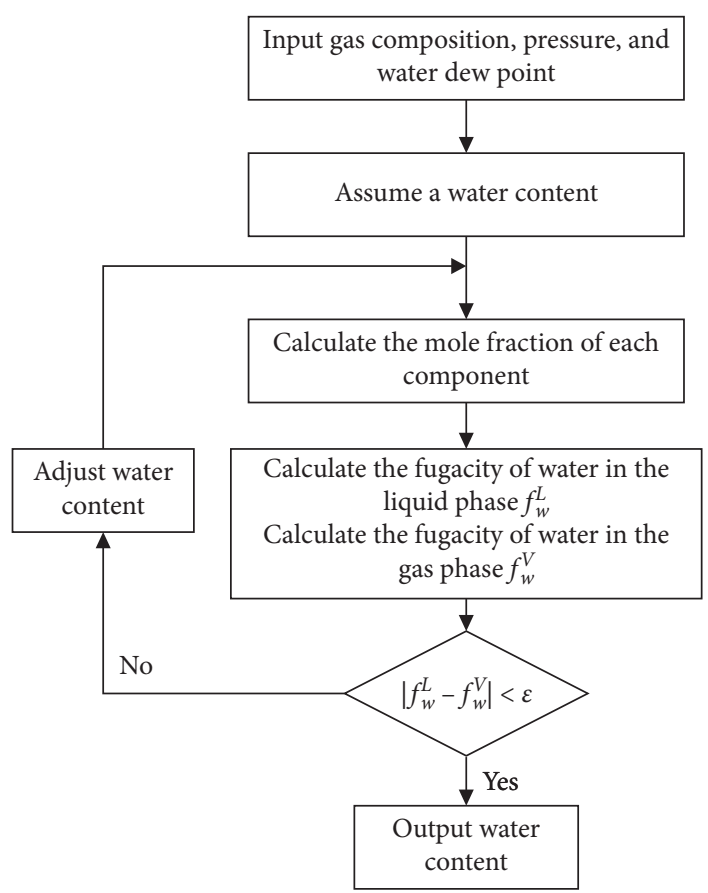

Figure 1: Steps to calculate water content based on the water dew point.

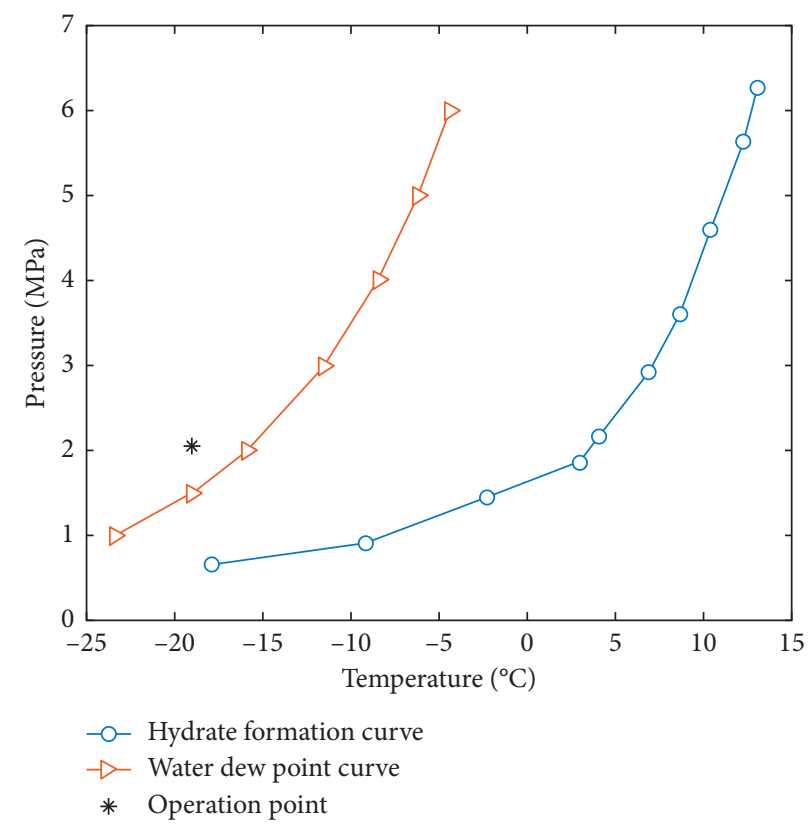

Figure 2: Analysis of hydrate formation in the throttling process of the gate station.

hydrate formation, and hydrate prevention measures are required.

\section{Hydrate Prevention and Control Measures}

The method of injecting thermodynamic inhibitors such as methanol/ethylene glycol is often used in the field to prevent and control hydrates. Based on safety considerations, the possibility of ethanol is discussed in this section. The injection volume of the thermodynamic inhibitor should include three parts, some dissolved in the liquid phase, some volatilized in the gas phase, and the other dissolved in the liquid hydrocarbon phase. The inhibitory part is the part dissolved in the liquid phase. Considering the low content of heavy hydrocarbon components in the gas entering the gate station, only a small amount of liquid hydrocarbon precipitates in the throttling process, and the loss of inhibitors in the liquid hydrocarbon phase is ignored. 


\subsection{Calculation of the Mass Fraction of Inhibitor in Liquid} Phase. By reducing the activity of water in the aqueous solution, the stable temperature of hydrate phase equilibrium can be reduced, which is the main principle of the inhibitory effect of thermodynamic inhibitors [22]. In Section 2, the activity of water in the Chen-Guo model was discussed, as shown in formula (7). Therefore, the Chen-Guo model can still be used to analyze the prediction of hydrate formation with inhibitors, so as to calculate the liquid required amount of the three inhibitors.

The mole fraction of each component in the ideal solution is the concentration of the component. Considering the deviation between the actual solution and the ideal solution, the concept of activity is introduced. It characterizes the effective concentration of the component in the mixture, which can be expressed by molar fraction and activity coefficient as follows:

$$
a_{i}=x_{i} \gamma_{i}
$$

where $a_{i}$ is the activity for component $i, x_{i}$ is the mole fraction of component $i$ in the solution, and $\gamma_{i}$ is the activity coefficient for component $i$.

The activity coefficient can be calculated using the Wilson activity coefficient model [23]. The formula is as follows:

$$
\ln \gamma_{k}=1-\ln \left(\sum_{i=1}^{m} x_{i} \Lambda_{i k}\right)-\sum_{i=1}^{m} \frac{x_{i} \Lambda_{i k}}{\sum_{j=1}^{m} x_{j} \Lambda_{i j}},
$$

where $\Lambda_{i j}$ is the Wilson parameter value, which can be calculated by the following formula:

$$
\Lambda_{i j}=\frac{v_{j}}{v_{i}} \exp \left(-\frac{\lambda_{i j}-\lambda_{i i}}{\mathrm{RT}}\right),
$$

where $v_{i}$ and $v_{j}$ is the molar volume of the component $i$ and $j$, $\mathrm{m}^{3} / \mathrm{mol}$, and $\lambda_{i j}-\lambda_{i i}$ is the energy parameter of the binary interaction between the components.

The activity of water in the liquid phase can be obtained using formulas (8)-(10), which is substituted into formula (7) of the Chen-Guo model to iteratively solve the mass fraction of the inhibitor liquid phase. The result obtained should satisfy the requirement that the temperature at the most dangerous operating point (when the pressure and temperature are the smallest after pressure regulation) is greater than or equal to the hydrate formation temperature corresponding to the pressure at that point. Due to the high viscosity of ethylene glycol, $80 \%$ concentration is considered in calculation.

3.2. Calculation of Total Injection Volume. Since methanol and ethanol have strong volatility, their loss in the gas phase needs to be considered. The process of total injection volume calculation is essentially considered as a gas-liquid isothermal flash calculation.

The steps for calculating the total injection volume are shown in Figure 3.

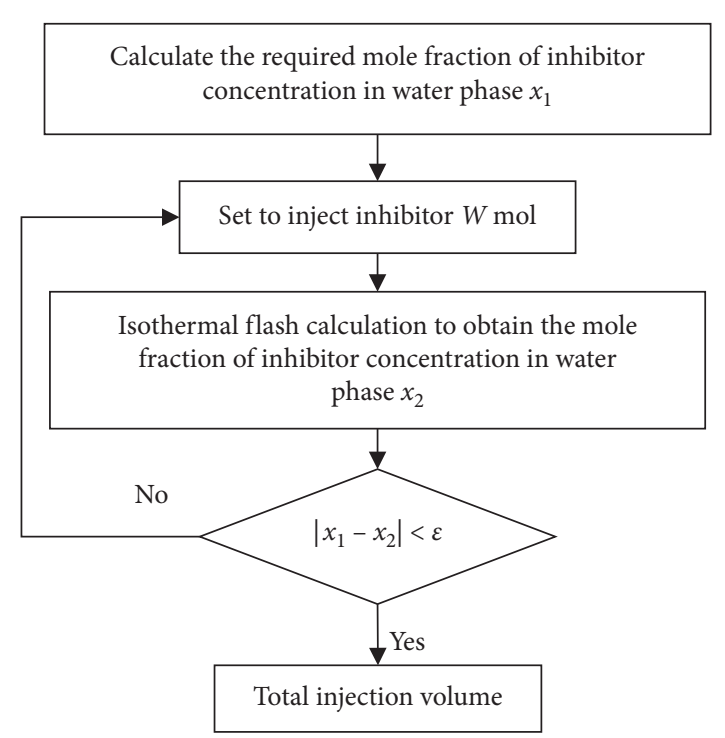

FIGURE 3: Block diagram of calculation steps for total injection volume.

The initial step is to calculate the required inhibitor concentration in the liquid phase by combining the Wilson activity coefficient model with the Chen-Guo model. Then, set the initial value of the molar amount of the inhibitor injected to $1 \mathrm{~mol}$ natural gas, and perform gas-liquid twophase isothermal flash calculation at the temperature and pressure after throttling to obtain the initial value of the mole fraction of each substance in the water and inhibitorcontaining gas system. Next, judge whether the difference between the concentration of the inhibitor in the liquid phase and the required concentration meets the accuracy requirements; if it meets the requirements, stop the calculation; otherwise, change the mole amount of the inhibitor injected until the accuracy meets the requirements. Because within a certain concentration range, when the mole amount of the inhibitor injected to $1 \mathrm{~mol}$ natural gas increases, the concentration of the inhibitor in the liquid phase also increases; the two are positively correlated, so the dichotomy method is used for iterative calculation.

Finally, the mole amount of the inhibitor needed to be injected in $1 \mathrm{~mol}$ natural gas can be obtained as the output and converted into the volume of the inhibitor needed to be injected in each $10^{4} \mathrm{Nm}^{3}$ natural gas by unit conversion.

\section{Results and Discussion}

4.1. Program Interface. Based on the above analysis, the hydrate prediction and prevention simulator program can be developed. There are two calculation interfaces in the program; the first interface is shown in Figure 4, and the second one is shown in Figure 5.

In Figure 4, the calculation interface of throttling process parameters can realize the mutual conversion of water dew point and water content, calculate throttling temperature drop, and judge whether there is water condensation in the throttling process. The actual water content of natural gas 


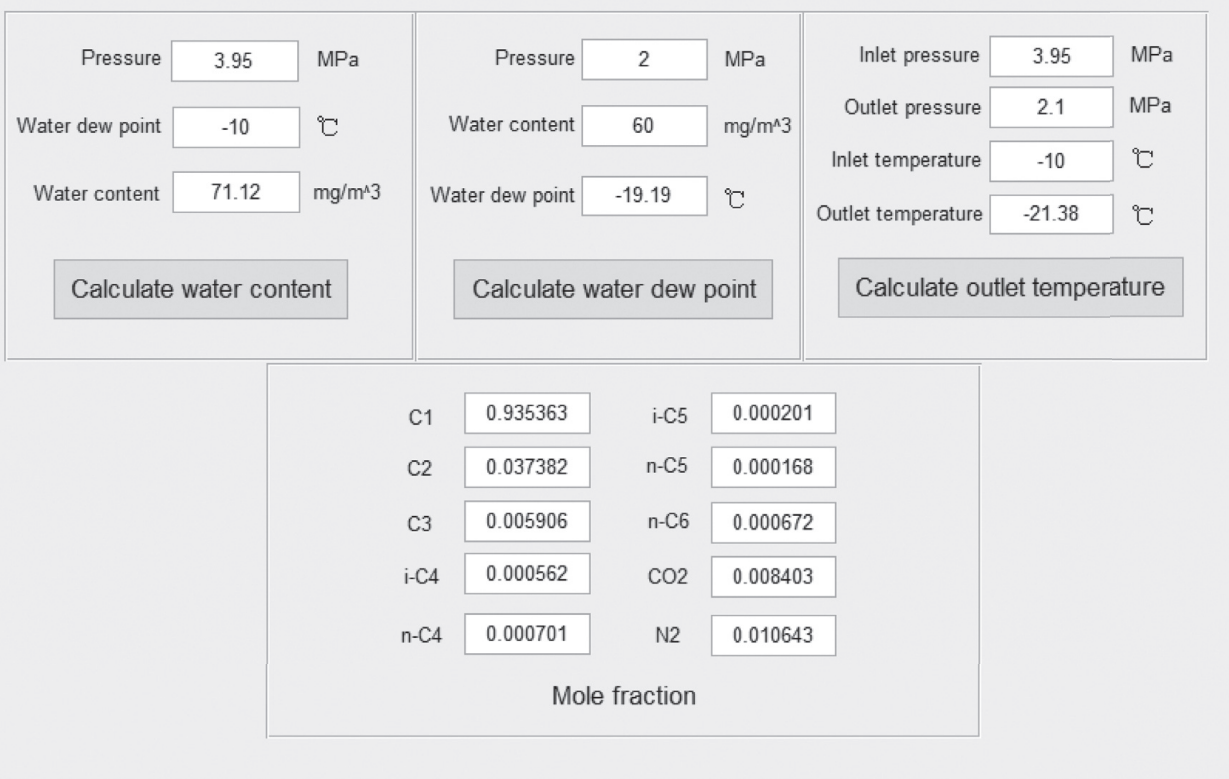

FIgURE 4: Calculation interface of throttling process parameters.

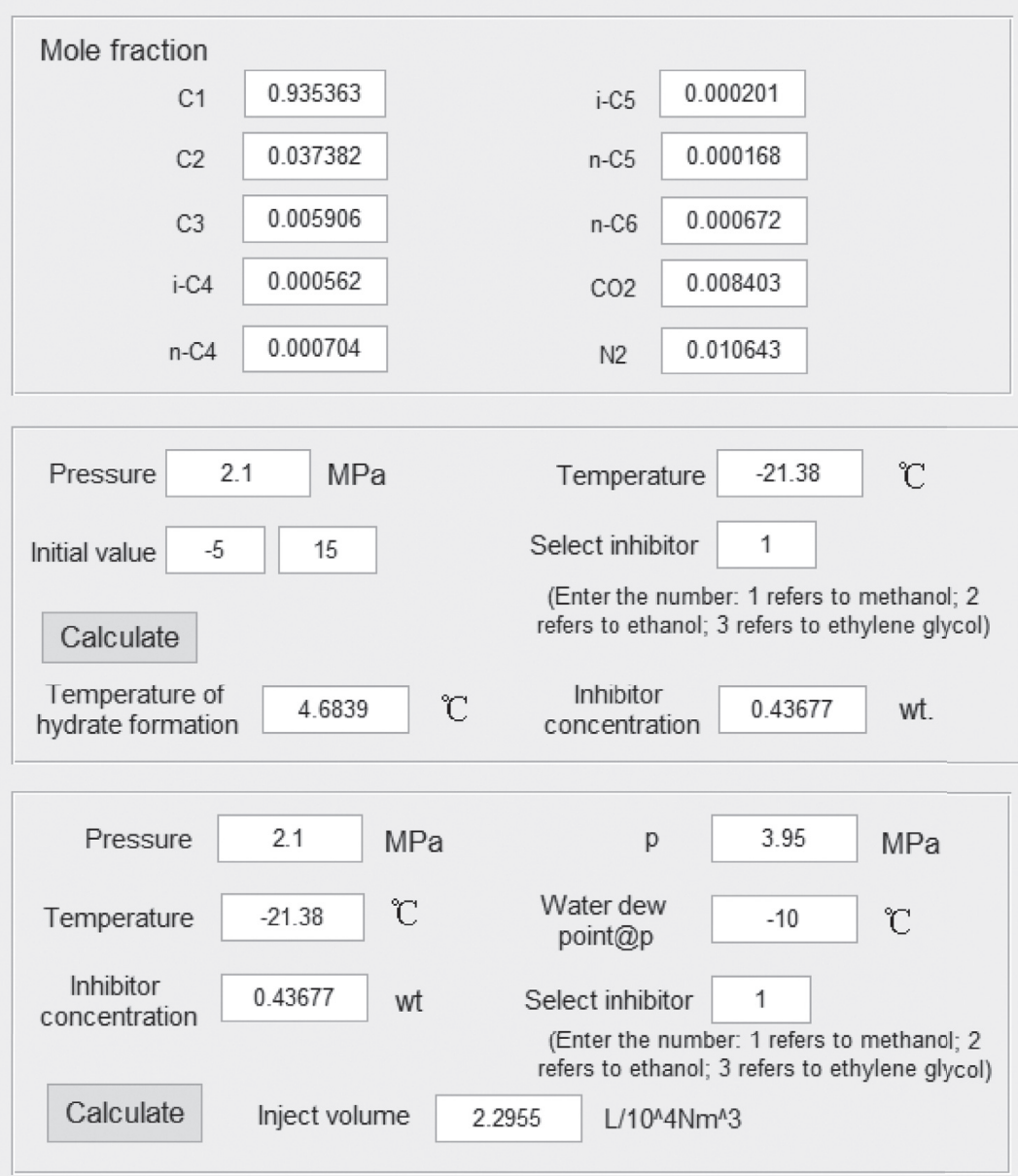

FIGURE 5: Calculation interface of hydrate prediction and prevention. 
can be calculated according to the pressure and water dew point before throttling. The maximum water content of the gas can be calculated according to the pressure and temperature after throttling. If the actual water content is greater than the maximum water content, there will be water condensation. At the same time, it can also be calculated to determine the water dew point index of noncondensable water before throttling, which is to calculate the maximum water content according to the temperature and pressure after the throttling, and converge the result obtained to the water dew point under the pressure before throttling, which should be higher than the known water dew point value before throttling to prevent water condensation.

In Figure 5, the hydrate formation temperature can be calculated according to the Chen-Guo model, and the required inhibitor concentration in the liquid phase can be calculated according to the Wilson activity coefficient and the Chen-Guo model, and then, the volume of inhibitor injected to prevent hydrate formation can be calculated by isothermal flash. For the operating condition with water condensation, it needs to input the water dew point, the corresponding pressure and dry gas components, the mole fraction of the inhibitor required for the liquid-phase, and finally temperature and pressure after throttling. Thus, the inhibitor's total injection volume can be calculated.

4.2. Result Verification. Taking the typical pressure regulation condition (3.95 2.10 MPa) as an example, the injection volume of the inhibitor required under different temperature before throttling and water dew point was calculated by using the simulator program and compared with the HYSYS calculation results, as shown in Table 1 . Select Ng-Robinson as the hydrate thermodynamic model in HYSYS.

Table 1 shows that when the pressure before and after throttling is known and the temperature before throttling is given, the inhibitor injection volume calculated by the program is close to the calculation results of HYSYS, and the absolute value of the error is between $0 \sim 0.09 \mathrm{~L} / 10^{4} \mathrm{Nm}^{3}$. The calculation accuracy meets engineering requirements.

Also, among the three inhibitors, the injection volume of the ethylene glycol inhibitor is the lowest and the injection volume of ethanol is the highest among the three inhibitors. The main reason is that, under the same conditions, the mass fraction of ethanol required in the liquid phase is much greater than that of methanol and ethylene glycol. It means that, under these conditions, the inhibitory effect of ethanol on hydrates is poor.

4.3. Discussion on the Effect and Economy of Inhibitors. Considering that the inhibitor in the liquid phase is the main part of the inhibitor's inhibitory effect, in order to analyze and compare the inhibitory effects of the three inhibitors more vividly, the program is used to calculate the liquid mass fractions of the three inhibitors in the liquid phase under different temperature $\left(-8^{\circ} \mathrm{C} \sim 3^{\circ} \mathrm{C}\right)$ and different pressures (2.1 $\mathrm{MPa}$ and $4 \mathrm{MPa}$ ) after throttling, as shown in Figure 6, where the gas composition used in different working conditions remains the same.

Figure 6 shows that, under the same condition, the mass fraction of thermodynamic inhibitors required in the liquid phase increases with the decrease of the temperature after throttling. When the pressure is $2.1 \mathrm{MPa}$, it can be seen from the figure that there is an intersection between $2^{\circ} \mathrm{C}$ and $3^{\circ} \mathrm{C}$, where the temperature value is about $2.4^{\circ} \mathrm{C}$. When the temperature after throttling is lower than the intersection temperature, the mass fraction of the required methanolwater solution is the least, and when the temperature after throttling is higher than this temperature, the mass fraction of the required ethanol-water solution is the least. When the pressure is $4 \mathrm{MPa}$, the mass fraction of the methanol aqueous solution is the least at any temperature. Thus, only methanol has the best inhibitory effect among the three inhibitors, followed by ethylene glycol. Moreover, it can be seen from the figure that, as the pressure decreases, the amount of inhibitor decreases, and the amount of ethanol decreases the most. Ethanol inhibitors have better inhibitory effect mainly under the conditions of high temperature and low pressure after throttling.

From the perspective of inhibitory effect, the mass fraction of methanol required is the least under the same condition. However, due to the strong volatility of methanol, its loss in the gas phase is large so that the total injection amount of methanol in Table 1 is greater than that of ethylene glycol.

In addition to considering the inhibitory effect, the final inhibitor selection must also be economical. For the gate station studied in this article, considering that the operating conditions after throttling are mostly concentrated in the pressure range of $2.00 \mathrm{MPa} \sim 2.10 \mathrm{MPa}$ and the temperature range of $-16^{\circ} \mathrm{C} \sim-22^{\circ} \mathrm{C}$, the inhibitory effect of ethanol is poor under this condition, and ethanol is the most expensive; hence, only the economics of methanol and ethylene glycol will be discussed below. The price of methanol is 3,000 yuan/ton, and the price of ethylene glycol is 4,800 yuan/ton. The calculation of the total investment cost within 3 years is considered (the winter supply period is 4 months, 30 days per month, and the calculated flow rate is $30 \times 10^{4} \mathrm{~m}^{3} / \mathrm{h}$ ), without considering the use of a glycol inhibitor recovery device to reuse it. The price of natural gas fuel is $2.5 \mathrm{yuan} / \mathrm{m}^{3}$. The temperature, pressure, and water dew point parameters of the three working conditions are shown in Table 2.

Since methanol will volatilize into the gas phase and mix with natural gas, when natural gas handover settlement occurs, this part of the gas may be considered as natural gas to be sold to the docking downstream users, which will generate certain benefits to the station. Therefore, when calculating the total cost of methanol, there are two situations. Situation 1 is to consider benefits of the gas phase of the inhibitor, and situation 2 is not to consider.

Finally, the total investment costs of the two inhibitors in the three-year operation period are shown in Table 3.

It can be seen from Table 3 that when not considering benefits of the gas phase of the inhibitor, it is more economical to choose the method of ethylene glycol injection 


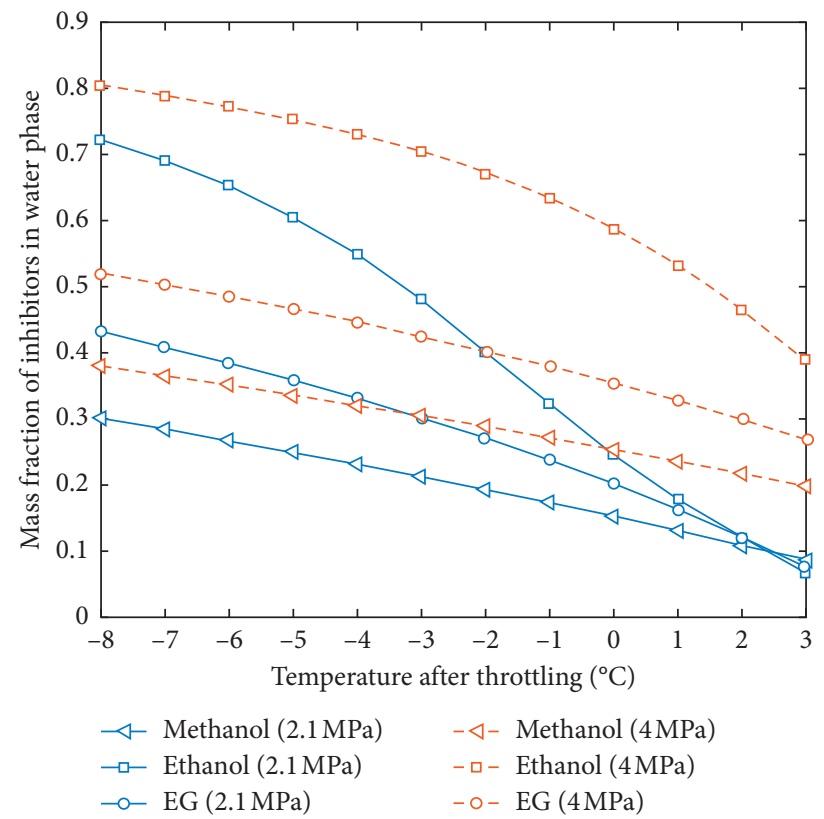

Figure 6: Comparison of inhibitory effect of different inhibitors.

TABLE 1: Comparison of inhibitor injection volume calculation.

\begin{tabular}{|c|c|c|c|c|c|c|c|c|c|c|}
\hline \multirow[t]{2}{*}{$\begin{array}{l}\text { Temperature before throttling } \\
\left({ }^{\circ} \mathrm{C}\right)\end{array}$} & \multirow[t]{2}{*}{$\begin{array}{l}\text { Water dew point } \\
\left({ }^{\circ} \mathrm{C}\right)\end{array}$} & \multicolumn{3}{|c|}{$\begin{array}{l}\text { Injection volume of } \\
\text { methanol } L\left(10^{4} \mathrm{Nm}^{3}\right)\end{array}$} & \multicolumn{3}{|c|}{$\begin{array}{l}\text { Injection volume of } \\
\text { ethanol } L\left(10^{4} \mathrm{Nm}^{3}\right)\end{array}$} & \multicolumn{3}{|c|}{$\begin{array}{l}\text { Injection volume of } \\
\text { ethylene glycol } L \\
\left(10^{4} \mathrm{Nm}^{3}\right)\end{array}$} \\
\hline & & HYSYS & Program & Abs. e & HYSYS & Program & Abs. e & HYSYS & Program & Abs. e \\
\hline \multirow{5}{*}{-5} & -5 & 3.02 & 3.01 & 0.01 & 3.24 & 3.26 & 0.02 & 0.89 & 0.87 & 0.02 \\
\hline & -6 & 2.95 & 2.94 & 0.01 & 3.19 & 3.19 & 0 & 0.77 & 0.76 & 0.01 \\
\hline & -7 & 2.88 & 2.88 & 0 & 3.12 & 3.13 & 0.01 & 0.68 & 0.66 & 0.02 \\
\hline & -8 & 2.82 & 2.82 & 0 & 3.06 & 3.07 & 0.01 & 0.58 & 0.56 & 0.02 \\
\hline & -9 & 2.76 & 2.77 & 0.01 & 3.00 & 3.02 & 0.02 & 0.47 & 0.47 & 0 \\
\hline \multirow{5}{*}{-10} & -10 & 2.76 & 2.67 & 0.09 & 2.86 & 2.92 & 0.06 & 0.95 & 0.91 & 0.04 \\
\hline & -11 & 2.69 & 2.61 & 0.08 & 2.81 & 2.86 & 0.05 & 0.84 & 0.80 & 0.04 \\
\hline & -12 & 2.63 & 2.56 & 0.07 & 2.75 & 2.81 & 0.06 & 0.75 & 0.70 & 0.05 \\
\hline & -13 & 2.57 & 2.51 & 0.06 & 2.70 & 2.76 & 0.06 & 0.64 & 0.61 & 0.03 \\
\hline & -14 & 2.52 & 2.45 & 0.07 & 2.65 & 2.7 & 0.05 & 0.56 & 0.52 & 0.04 \\
\hline
\end{tabular}

TABLE 2: Parameters of the three working conditions.

\begin{tabular}{lcccc}
\hline & Temperature before throttling $\left({ }^{\circ} \mathrm{C}\right)$ & $\begin{array}{c}\text { Pressure before throttling } \\
(\mathrm{MPa})\end{array}$ & Water dew point $\left({ }^{\circ} \mathrm{C}\right)$ & Pressure after throttling $(\mathrm{MPa})$ \\
\hline Condition 1 & 0 & 3.95 & 0 & 2.10 \\
Condition 2 & -5 & 3.95 & -5 & 2.10 \\
Condition 3 & -10 & 3.95 & -10 & 2.10 \\
\hline
\end{tabular}

TABle 3: Total investment costs of the two inhibitors.

\begin{tabular}{lccc}
\hline & \multicolumn{2}{c}{ Methanol (per 10,000 yuan) } & Ethylene glycol (per 10,000 yuan) \\
\hline Condition 1 & Situation 1 & Situation 2 & 89.6 \\
Condition 2 & 80.3 & 165 & 104.4 \\
Condition 3 & 81.7 & 167 & 108.2 \\
\hline
\end{tabular}


for hydrate prevention and control, and when considering benefits of the gas-phase of the inhibitor, the method of methanol injection is economical.

\section{Conclusion}

In this paper, a quick and convenient program to predict and prevent hydrate formation for city gate stations is developed. After inputting the gas composition, pressure and temperature before throttling, and water dew point and pressure after throttling, hydrate formation temperature can be calculated. The required mass fraction of the inhibitor in the liquid phase and the injection volume of a thermodynamic inhibitor to prevent hydrate formation for city gate stations can be obtained. Based on the research, some remarkable conclusions can be drawn as follows:

(1) Using the developed program, the result of the inhibitor injection volume is close to HYSYS, and the absolute value of the error is between $0 \sim 0.09 \mathrm{~L} /$ $10^{4} \mathrm{Nm}^{3}$, which has a certain engineering guiding significance.

(2) In addition to the calculation of commonly used methanol and ethylene glycol inhibitors, this article considers the use of ethanol for inhibition for the first time from a safety perspective. The calculation results show that ethanol is mainly suitable for the operating conditions with higher temperature and lower pressure after throttling.

(3) Applying the program to the actual working conditions of a certain gate station, from the point of view of the suppression effect, methanol has the best suppression effect among the three inhibitors, followed by ethylene glycol. Due to the large loss of methanol in the gas phase, the total injection volume of the inhibitor is the least of ethylene glycol. From an economic point of view, this article highlighted the benefits brought by the volatilization of inhibitors to the gas phase when natural gas is delivered. Finally, it is recommended to use methanol injection for hydrate prevention and control. Moreover, if the gas phase benefits of the inhibitor are not considered, the method of ethylene glycol injection is more economical.

\section{Data Availability}

The data used to support the findings of this study are included within the article.

\section{Conflicts of Interest}

The authors declare that they have no conflicts of interest.

\section{References}

[1] D. Q. Li, M. Y. Ai, Y. B. Wang et al., "Hydrate accident and prevention in sebei-xining-lanzhou gas pipeline," Oil \& Gas Storage and Transportation, vol. 31, no. 4, pp. 267-269, 2012.
[2] C. Y. Sun, Q. Huang, and G. J. Chen, "Progress of thermodynamics and kinetics of gas hydrate formation," Journal of Chemical Industry and Engineering (China), no. 5, pp. 10311039, 2006.

[3] B. Y. Liu, M. Hao, and B. D. Chen, "Prediction of maximal allowable water content in long distance pipelines," Journal of Petrochemical Universities, no. 2, pp. 75-78, 2004.

[4] B. H. Shi, K. Quan, G. C. Qiao et al., "Prevention measures for hydrate ice blockage in Yu-Ji gas pipeline," Oil \& Gas Storage and Transportation, vol. 33, no. 3, pp. 274-278, 2014.

[5] B. H. Shi, Y. L. Qian, H. Q. Wang et al., "Calculation method of water content/water dew point of natural gas," Oil \& Gas Storage and Transportation, vol. 31, no. 3, pp. 188-192, 2012.

[6] M. Mesbah, S. Habibnia, S. Ahmadi et al., "Developing a robust Correlation for prediction of sweet and sour gas hydrate formation temperature," Petroleum, 2020.

[7] J. H. Waals and J. C. Platteeuw, "Clathrate solutions," Advances in Chemical Physics, vol. 2, pp. 1-57, 1958.

[8] G. Chen and T. Guo, "Thermodynamic modeling of hydrate formation based on new concepts," Fluid Phase Equilibria, vol. 122, no. 1, pp. 43-65, 1996.

[9] M. Motiee, "Estimate possibility of hydrates," Hydrocarbon Processing, vol. 70, no. 7, pp. 98-99, 1991.

[10] K. K. Ostergaard, B. Tohidi, and A. Danesh, “A general correlation for predicting the hydrate-free zone of reservoir fluids," SPE Production \& Facilities, vol. 15, no. 4, pp. 228-233, 2000.

[11] B. F. Towler and S. Mokhatab, "Quickly estimate hydrate formation conditions in natural gases," Hydrocarbon Processing, vol. 84, no. 4, pp. 61-62, 2005.

[12] W. C. Wang, Y. X. Li, S. S. Fan, D. Liang et al., "Hydrate inhibiting policy based on risk management for oil and gas pipelines," Natural Gas Industry, vol. 30, no. 10, pp. 69-72, 2010.

[13] Y. H. Du and T. M. Guo, "The prediction of hydrate formation conditions of natural gas II;. inhibitor containing systems," Acta Petrolei Sinica (Petroleum Processing Section), no. 4, pp. 67-76, 1988.

[14] Q. L. Ma, G. J. Chen, and T. M. Guo, "Modelling the gas hydrate formation of inhibitor containing systems," Fluid Phase Equilibria, vol. 205, no. 2, pp. 291-302, 2003.

[15] E. Khosravani, G. Moradi, and S. Sajjadifar, "An accurate thermodynamic model to predict phase behavior of clathrate hydrates in the absence and presence of methanol based on the genetic algorithm," Journal of Chemical Thermodynamics, vol. 57, pp. 286-294, 2013.

[16] M. Ayijiamal, Y. X. Li, Y. Q. Che et al., "Hydrate control scheme of hutubi gas storage and its optimization," Oil \& Gas Storage and Transportation, vol. 36, no. 9, pp. 1024-1029, 2017.

[17] Z. Guo, X. Jing, and Y. S. Cao, "Calculate the injection volume of natural gas hydrate inhibitor by HYSYS," Oil and Gas Treating and Processing, vol. 31, no. 6, pp. 49-51, 2013.

[18] R. Davarnejad and J. Azizi, "Prediction of gas hydrate formation using HYSYS software," International Journal of Engineering-Transactions C: Aspects, vol. 27, no. 9, pp. 1325-1330, 2014.

[19] S. G. Li, Y. J. Li, L. B. Yang et al., "Prediction of phase equilibrium of gas hydrates based on different equations of state," Journal of Chemical Industry and Engineering (China), vol. 69, no. S1, pp. 8-14, 2018.

[20] D. Y. Peng and D. B. Robinson, "A new two-constant equation of state," Industrial \& Engineering Chemistry Fundamentals, vol. 15, no. 1, pp. 59-64, 1976. 
[21] G. J. Chen, Q. L. Ma, and T. M. Guo, "A new mechanism for hydrate formation and development of thermodynamic model," Journal of Chemical Industry and Engineering (China), no. 5, pp. 52-57, 2000.

[22] X. Zhao, Z. S. Qiu, W. A. Huang et al., "Inhibition mechanism and optimized design of thermodynamic gas hydrate inhibitors," Acta Petrolei Sinica, no. 6, pp. 124-130, 2015.

[23] Y. F. Yu, B. H. Shi, J. Q. Wang et al., "A calculation method for the critical minimum dosage of hydrate thermodynamic inhibitor," Oil \& Gas Storage and Transportation, vol. 38, no. 5, pp. 547-553, 2019. 